\title{
Detection of Epstein-Barr virus infection subtype in patients with multiple sclerosis by indirect immunofluorescence assay
}

\author{
Shan-Chao Zhang ${ }^{1}$, Lei Liư ${ }^{2}$, Rui-Jin Wang ${ }^{1}$, Hou-Zhen Tuo ${ }^{1}$, Yan-Jun Guo ${ }^{1}$, Li Yi ${ }^{1}$, De-Xin Wang ${ }^{1}$, Jia-Wei Wang ${ }^{2}$ \\ ${ }^{1}$ Department of Neurology, Beijing Friendship Hospital, Capital Medical University, Beijing 100050, China. \\ ${ }^{2}$ Department of Neurology, Beijing Tongren Hospital, Capital Medical University, Beijing 100730, China.
}

\section{A B S T R A C T}

Aim: The aim was to investigate the infectious conditions of Epstein-Barr virus (EBV) in patients with multiple sclerosis (MS). Methods: Cerebrospinal fluid (CSF) of 20 patients with MS and 20 with other neurological diseases (OND) were tested with indirect immunofluorescence for anti-EBV capsid antigen (EBV-CA) immunoglobulin G (IgG), IgG affinity for anti-EBV-CA, anti-EBV-CA immunoglobulin $\mathrm{M}(\mathrm{IgM})$, anti-EBV early antigen (EBV-EA) IgG and anti-EBV nuclear antigen (EBNA) IgG. According to the pattern of antibodies in CSF, infection rates of acute, chronic, primary, recurrent, and past infections were analyzed in the two groups of patients. Results: There were no significant differences in anti-EBV-CA, anti-EBC-EA, and anti-EBNA antigen IgG in CSF between MS and OND patients $(P>0.05)$. The positive rate of low affinity for anti-EBV-CA IgG in MS patients was significantly higher than that for OND patients $(75 \%$ vs. $40 \%, P<0.05)$. Furthermore, significant differences in the positive rate of anti-EBV-CA IgM were found between MS and OND patients $(70 \%$ vs. $25 \%, P<0.05)$. Of the MS patients, $75 \%$ were in an EBV acute infection state compared with $40 \%$ of OND patients $(P<0.05)$. Conclusion: Acute infection of EBV closely correlates with the occurrence of MS.

Key words: Epstein-Barr virus, fluorescent antibody technique, herpes virus 4, multiple sclerosis

\section{INTRODUCTION}

Multiple sclerosis (MS) is an autoimmune demyelinating disease of the central nervous system, the etiology and pathogenesis of which are currently poorly understood, but are known to be primarily associated with genetic and environmental factors. ${ }^{[1,2]}$ However, recent studies have shown that bacteria and viruses are closely related to the incidence of MS. The characteristic of Epstein-Barr virus (EBV) infection, as a latent infection with periodic recurrence, makes EBV a risk factor for MS. ${ }^{[3]}$ According to an epidemiological survey of MS and infectious mononucleosis patients, the experimental

\begin{tabular}{|l|l|}
\hline \multicolumn{2}{|c|}{ Access this article online } \\
\hline Quick Response Code: & \\
\hline & Website: \\
\hline & www.nnjournal.net \\
& \\
\hline
\end{tabular}

results indicate that the high incidence of MS is correlated with EBV genetic susceptibility in patients. Serum epidemiological and immunological evidences also show that the incidence of MS is significantly higher in serum EBV antigen-antibody-positive patients than in serum antibody-negative patients. ${ }^{[4,5]}$ In addition, EBV capsid antigen (EBV-CA) and EpsteinBarr nuclear antigen (EBNA) antibody titers may be associated with the prevalence of MS. ${ }^{\left[{ }^{[6}\right.}$ Previous studies were based on enzyme-linked immunosorbent assay (ELISA) to confirm the relationship between serum/cerebrospinal fluid (CSF) EBV antigen-antibody and the occurrence of MS. This method did not, however, show details of the type of EBV infection. In contrast, indirect immunofluorescence assay (IFA) can not only compensate for this ELISA defect, but also has the advantage of using a standardized preparation..$^{[7,8]}$ As a result, our study has used IFA to reveal the correlation of MS with EBV antigen-antibody and thus, provide a better method for diagnosis and treatment of MS.

Corresponding Author: Dr. Jia-Wei Wang, Department of Neurology, Beijing Tongren Hospital, Capital Medical University, No. 1 Dong Jiao Min Xiang, Dongcheng District, Beijing 100730, China. E-mail: wangiwcq@163.com 


\section{METHODS}

\section{Participants}

A total of 20 patients with MS, of which 6 males and 14 females were examined at Beijing Friendship Hospital from 2002 to 2010 and were enrolled in this study. MS was defined using the 2010 McDonald criteria for MS. ${ }^{[9]}$ Among the patients, 14 had relapsing remitting MS, 2 had progressive remitting MS, 3 had primary progressive MS, and 1 had secondary progressive MS. None of the patients had been treated with corticosteroids or immunosuppressive agents 2 months before hospital admittance. Demographic data were collected from the patients by retrospective review of their medical records.

Twenty further patients were recruited with other neurological diseases (OND), including 9 with peripheral neuropathy, 4 with Parkinson's disease, 2 with headache, 2 with neurosis, 2 with motor neuron disease and 1 with cerebellar ataxia. Any OND patients with immunological diseases were excluded. There was no statistically significant difference $(P>0.05)$ in age and gender composition of the MS and OND patients.

This study was approved by the Capital Medical University Affiliated Beijing Friendship Hospital Ethics Committee. Written informed consents were obtained from individuals who participated in this study.

\section{Anti-EBV antibody assay}

The presence of anti-EBV antibodies, including anti-EBV-CA immunoglobulin G (IgG), anti-EBV-CA IgG affinity, anti-EBV-CA immunoglobulin M (IgM), anti-EBV early antigen (EBV-EA) IgG and anti-EBNA IgG, were assayed as described previously. Green florescence indicated that CSF had related antigen-antibody (positive reaction). Anti-EBV-CA IgG antibody affinity was assayed according to the green florescence intensity of urea-treated CSF parallel with physiological saline-treated CSF ${ }^{[10]}$ The intensity of florescence was depicted as follows: 0 referred to no florescence, 1 to very weak florescence, 2 to weak florescence, 3 to moderate florescence, 4 to strong florescence and 5 to very intense florescence. High antibody affinity indicated that the rate difference between urea-treated CSF florescence intensity and physiological saline-treated CSF florescence intensity was lower than two grades, while low antibody affinity was equal or higher than two grades. Antibody affinity is unable to be assayed when florescence intensity of physiological saline-treated CSF is lower than two grades.

The different EBV infection subtypes are shown in Table 1. ${ }^{[11]}$

\begin{tabular}{|c|c|c|c|c|}
\hline \multirow{2}{*}{$\begin{array}{l}\text { Infection } \\
\text { type }\end{array}$} & \multicolumn{2}{|c|}{ Anti-EBV-CA } & \multirow{2}{*}{$\begin{array}{l}\text { Anti-EBV- } \\
\text { EA IgG } \\
\text { antibody }\end{array}$} & \multirow{2}{*}{$\begin{array}{l}\text { Anti-EBNA } \\
\text { IgG antibody }\end{array}$} \\
\hline & $\begin{array}{l}\text { IgG } \\
\text { antibody }\end{array}$ & $\begin{array}{l}\text { IgM } \\
\text { antibody }\end{array}$ & & \\
\hline $\begin{array}{l}\text { Acute } \\
\text { infection }\end{array}$ & $\begin{array}{l}\text { Low antibody } \\
\text { affinity }\end{array}$ & Positive & - & Negative \\
\hline $\begin{array}{l}\text { Chronic } \\
\text { infection }\end{array}$ & $\begin{array}{l}\text { High antibody } \\
\text { affinity }\end{array}$ & - & Positive & Negative \\
\hline $\begin{array}{l}\text { Primary } \\
\text { infection }\end{array}$ & Negative & - & Positive & Negative \\
\hline $\begin{array}{l}\text { Recurrence } \\
\text { after infection }\end{array}$ & $\begin{array}{l}\text { High antibody } \\
\text { affinity }\end{array}$ & - & Positive & Positive \\
\hline Past infection & $\begin{array}{l}\text { High antibody } \\
\text { affinity }\end{array}$ & - & Negative & Positive \\
\hline
\end{tabular}

EBV: Epstein-Barr virus, CA: Capsid antigen, EA: Early antigen, IgG: Immunoglobulin G, IgM: Immunoglobulin M, EBNA: Epstein-Barr nuclear antigen

\section{Statistical analysis}

SPSS for Windows version 15.0 (SPSS Inc., Armonk, NY, USA) was used for statistical analysis. The difference between two means was tested by $\chi^{2}$ and Fisher's exact probability test. $P<0.05$ was considered as statistically significant.

\section{RESULTS}

Detection of CSF EBV related antibody in MS/OND patients Figure 1 shows the positive/negative reactions of the antibodies of anti-EBNA IgG, anti-EBV-CA IgG, anti-EBV-CA IgM, and anti-EBV-EA IgG. The antiEBV-CA IgG antibody affinity is indicated in Figure 2. There was no significant difference between MS and OND patients whose CSF had antibodies of anti-EBNA IgG, anti-EBV-EA IgG or anti-EBV-CA IgG $(P>0.05)$. However, there was a statistical difference between MS and OND patients whose CSF displayed high/low antiEBV-CA IgG antibody affinity or positive anti-EBV-CA IgM antibody $(P<0.05)$ [Table 2].

Composition of EBV infection type in MS and OND patients The MS group had 15 patients who suffered from EBV acute infection, while the OND group had only 5 patients. This difference between the groups was statistically significant. One patient in the MS group had a recurrence after an EBV infection, while this was not detected in anyone in the OND group. EBV past infection existed in $4 \mathrm{MS}$ and 12 OND patients, which was statistically different $(P<0.05)$. We failed to find an EBV chronic or primary infection in either MS or OND group.

\section{DISCUSSION}

EBV is a ubiquitous human DNA herpes virus. More than $90 \%$ of the world's population has been infected with EBV. EBV infection is closely related to 
the occurrence of nasopharyngeal carcinoma, Burkitt lymphoma, Hodgkin disease, and immunoblastic lymphoma. Children infected with EBV often display invisible symptoms. Adolescents and adults with EBV infection frequently suffer from infectious mononucleosis syndrome. In addition, EBV infection may correlate with the occurrence of some autoimmune diseases, such as systemic lupus erythematous ${ }^{[12]}$ or MS. ${ }^{[4]}$ Epidemiological investigations with patients

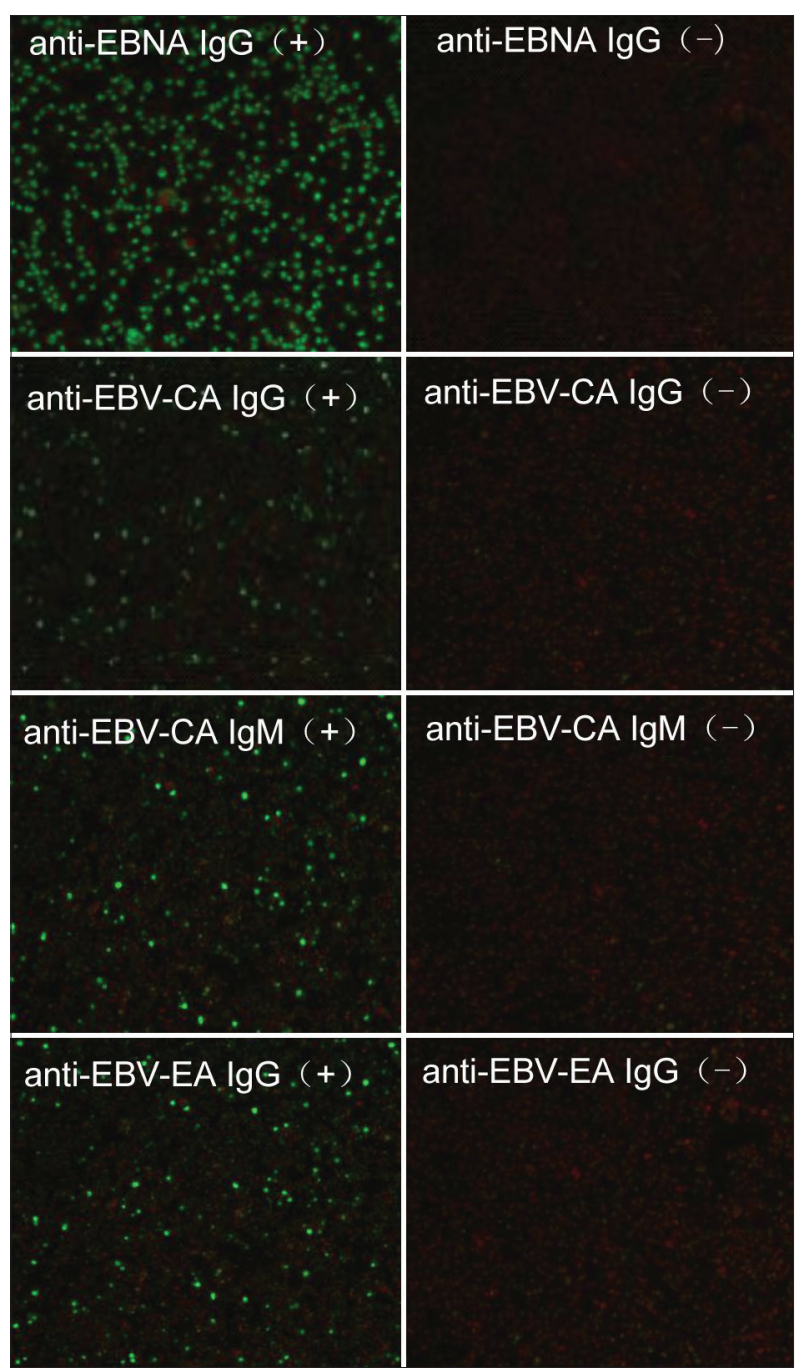

Figure 1: Detection of anti-EBNA IgG, anti-EBV-CA IgG, anti-EBV-CA IgM and anti-EBV-EA IgG in CSF. EBV antigen immunoglobulin antibody in CSF is indicated by green fluorescence. Red fluorescence reveals that EBV antigen immunoglobulin antibody is absent in CSF. EBV: Epstein-Barr virus; CA: Capsid antigen; EA: Early antigen; IgG: Immunoglobulin G; IgM: Immunoglobulin M; CSF: Cerebrospinal fluid; EBNA: Epstein-Barr nuclear antigen having infectious mononucleosis syndrome and MS show that MS often occurs in populations with high EBV genetic susceptibility. Serum epidemiological and immunological evidence also suggests that the probability of occurrence in MS patients with EBV antigen-antibody-positive serum is significantly higher than in the serum antibody-negative population. ${ }^{[5]}$ EBV-CA and EBNA antibody titer has also been associated with the prevalence of MS. ${ }^{[6]}$ Although previous studies using ELISA have confirmed the relationship between serum/CSF EBV antigen-antibody and MS, this assay fails to distinguish the EBV infection subtype. As a result of ELISA's poor reproducibility and the specificity of the antigen preparation and complexity, we used IFA in this experiment owing to IFA having merit with a conjugate-standardized preparation and in EBV-infection type differentiation. ${ }^{[7,8]}$

The IFA assay was used in $20 \mathrm{MS}$ and 20 OND patients to detect the CSF antibodies of anti-EBNA IgG, anti-EBV-CA IgG, anti-EBV-CA IgG antibody affinity, anti-EBV-CA

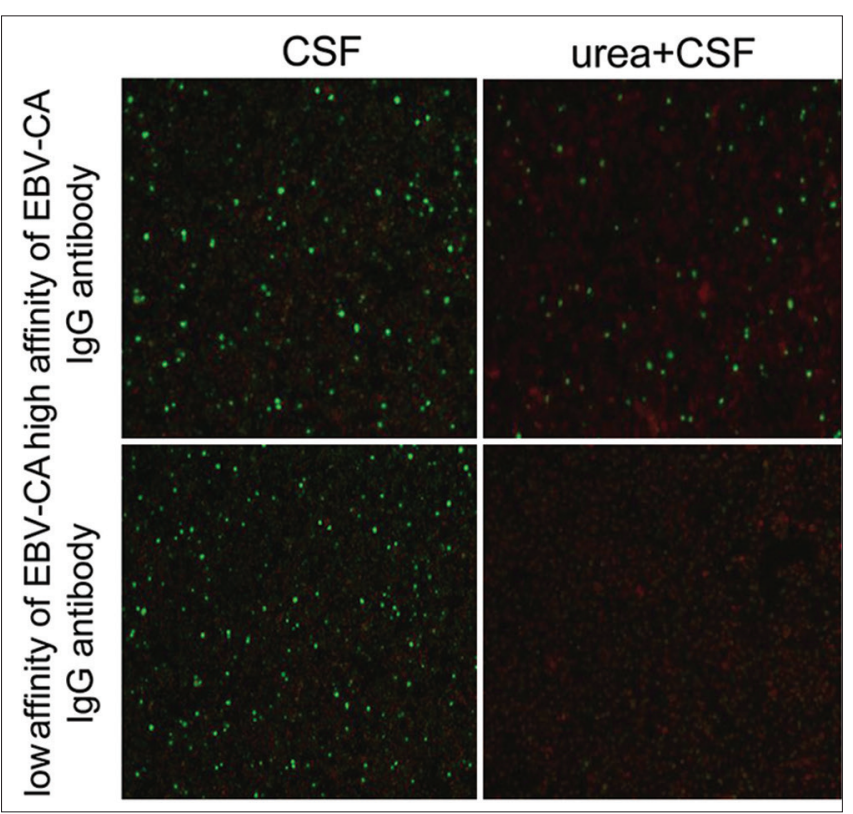

Figure 2: Detection of affinity of EBV-CA IgG. EBV-CA IgG antibody in CSF is indicated by green fluorescence. High affinity of antibody reveals that green fluorescence still exists after CSF is treated with urea. Disappearance of green fluorescence after CSF was treated with urea demonstrates low affinity of the antibody. EBV: Epstein-Barr virus; CA: Capsid antigen; EA: Early antigen; IgG: Immunoglobulin G; IgM: Immunoglobulin M; CSF: Cerebrospinal fluid; EBNA: Epstein-Barr nuclear antigen

\begin{tabular}{|c|c|c|c|c|c|c|}
\hline \multirow[t]{2}{*}{ Group } & \multirow{2}{*}{$\begin{array}{c}\text { Anti-EBNA } \\
\text { IgG }\end{array}$} & \multirow{2}{*}{$\begin{array}{c}\text { Anti-EBV-CA } \\
\text { IgM }\end{array}$} & \multirow{2}{*}{$\begin{array}{c}\text { Anti-EBV-EA } \\
\text { IgG }\end{array}$} & \multirow{2}{*}{$\begin{array}{c}\text { Anti-EBV-CA } \\
\text { IgG }\end{array}$} & \multicolumn{2}{|c|}{ Anti-EBV-CA IgG antibody affinity } \\
\hline & & & & & High & Low \\
\hline MS & $5(25)$ & $15(75)^{*}$ & $1(5)$ & $18(90)$ & $3(15)^{*}$ & $13(65)^{*}$ \\
\hline OND & $6(30)$ & $5(25)$ & $0(0)$ & $19(95)$ & $12(60)$ & $8(40)$ \\
\hline
\end{tabular}

Data are shown as $n(\%) .{ }^{*} P<0.05$ vs. OND. EBV: Epstein-Barr virus, CA: Capsid antigen, EA: Early antigen, IgG: Immunoglobulin G, IgM: Immunoglobulin M, MS: Multiple sclerosis, OND: Other neurological diseases, EBNA: Epstein-Barr nuclear antigen 
IgM, and anti-EBV-EA IgG. The results showed that the anti-EBNA IgG antibody-positive rate of the MS group was $25 \%$ compared with $30 \%$ in the OND group, but the difference was not statistically significant. Similarly, no statistically significant difference in the anti-EBNA IgG antibody-positive rate was found by Villegas et al. ${ }^{[13]}$ (6.6\% in MS patients and $17.0 \%$ in OND) and by Castellazzi et al. ${ }^{[14]}$ (6.3\% MS and 1.3\% in OND). In addition, Pohl et al. ${ }^{[15]}$ showed that the anti-EBNA IgG antibody-positive rate of MS patients was 8\%, similar to observations by Sargsyan et al. ${ }^{[16]}$ and Jafari et al. ${ }^{[17]}$ Our results support the above conclusions, but we found the anti-EBNA IgG antibody-positive rate was much higher than in these previous research reports. This difference may be explained by (1) different sample sizes, (2) the IFA used in our experiment which has a higher sensitivity than the ELISA assay in the previous studies, and (3) the EBV infection rate in China is higher than in European and American countries with better sanitary conditions. In our study, the positive rate of the CSF anti-EBNA IgG antibody in the MS group was lower than that in the OND group, which contrasts with the reports of Jaquiéry et al. ${ }^{[18]}$ and Cepok et al. ${ }^{[19]}$ This difference may be explained by the smaller sample size in our study and the different living environments and the genetic susceptibility of the European and American populations as compared to the Chinese.

Positive anti-EBV-CA IgG antibodies in human CSF suggest a past history of EBV infection. Our data showed that the positive rate of anti-EBV-CA IgG antibodies in MS patients was 90\% compared with 95\% in OND patients. This observation is also supported by other reports. ${ }^{[20,21]}$ The detection of anti-EBV-EA IgG antibody in CSF in our study represents either an acute or chronic EBV infection, suggesting that EBV reproduces. This has also been observed in a previous study. ${ }^{[22]}$ The high affinity for anti-EBV-CA IgG antibodies in MS and OND patients is characterized by EBV chronic or past infections, but a low affinity was found where there was an acute or a recurrent infection. ${ }^{[23]}$ The data revealed that the positive rate of low affinity antibodies was higher in the MS group than in OND patients, which paralleled with the results reported by Robertson et al. ${ }^{[10]}$ and Gray ${ }^{[23]}$ According to the positive/negative reactions of various EBV antigen-antibodies in the analysis of the EBV infection types, we found that the acute EBV infection rate in MS patients was significantly higher than that of the OND group (75\% vs. $40 \%$ ) while having a previous infection the rate was significantly lower than in the OND group (20\% vs. 60\%). This may suggest that acute EBV infections may be associated with the onset of MS. The EBV-specific super-antigens activate $\mathrm{CD}^{+} \mathrm{T}$ cells, which produce a cross-reaction with myelin protein through interaction with B and NK cells. $^{[24]}$ In addition, EBV can directly cause acute myelin oligodendrocyte glycoprotein-specific cellular and humoral immune responses, ${ }^{[25]}$ and simultaneously activate $\mathrm{CD} 8^{+} \mathrm{T}$ cells. Moreover, $\mathrm{CD} 8^{+} \mathrm{T}$ cells react with B cells infected with EBV for anti-myelin associated protein antibody production. ${ }^{[26]}$ However, our data are different with the results reported by Kiriyama et al. ${ }^{[27]}$ Further investigations are required to establish the pathogenesis of MS affected by EBV acute infections.

In summary, our study suggests that acute EBV infection is closely associated with the pathogenesis of MS, and that inhibition of EBV infection is beneficial to the prevention and treatment of MS. However, the prevalence of EBV infection is high in the general population, but the prevalence of MS is relatively low, which suggests there may be other MS causative factors, such as genetic predisposition, EBV primary infection, age and other microbial infections. As a result, further studies are necessary to investigate MS pathogenesis of EBV infections.

\section{ACKNOWLEDGEMENTS}

The work was supported by Beijing Natural Science Foundation (Nos. 7102040, 7132060), National Natural Science Foundation of China (Nos. 81041020, 81271311, and 81241039), Traditional Chinese Medicine, Beijing Technology Development Fund (No. SF-2007-III-22), Beijing Excellent Talent Foundation (No. 20071-D0300100062), the high-level technical training project funding of the Beijing Health System (2011-3-004) and the preferential funding scheme for Beijing city staff to go abroad.

\section{REFERENCES}

1. Hafler DA. Multiple sclerosis. J Clin Invest 2004;113:788-94.

2. Giovannoni G, Cutter GR, Lunemann J, Martin R, Münz C, Sriram S, Steiner I, Hammerschlag MR, Gaydos CA. Infectious causes of multiple sclerosis. Lancet Neurol 2006;5:887-94.

3. Haahr S, Höllsberg P. Multiple sclerosis is linked to Epstein-Barr virus infection. Rev Med Virol 2006;16:297-310.

4. De Jager PL, Simon KC, Munger KL, Rioux JD, Hafler DA, Ascherio A. Integrating risk factors: HLA-DRB1*1501 and Epstein-Barr virus in multiple sclerosis. Neurology 2008;70:1113-8.

5. Ascherio A, Munger K. Epidemiology of multiple sclerosis: from risk factors to prevention. Semin Neurol 2008;28:17-28.

6. Hunter SF, Hafler DA. Ubiquitous pathogens: links between infection and autoimmunity in MS? Neurology 2000;55:164-5.

7. Martins TB, Litwin CM, Hill HR. Evaluation of a multiplex fluorescent microsphere immunoassay for the determination of Epstein-Barr virus serologic status. Am J Clin Pathol 2008;129:34-41. 
8. de Ory F, Guisasola ME, Sanz JC, García-Bermejo I. Evaluation of four commercial systems for the diagnosis of Epstein-Barr virus primary infections. Clin Vaccine Immunol 2011;18:444-8.

9. Polman CH, Reingold SC, Banwell B, Clanet M, Cohen JA, Filippi M, Fujihara K, Havrdova E, Hutchinson M, Kappos L, Lublin FD, Montalban X, O'Connor P, Sandberg-Wollheim M, Thompson AJ, Waubant E, Weinshenker B, Wolinsky JS. Diagnostic criteria for multiple sclerosis: 2010 revisions to the McDonald criteria. Ann Neurol 2011;69:292-302.

10. Robertson P, Beynon S, Whybin R, Brennan C, Vollmer-Conna U, Hickie I, Lloyd A. Measurement of EBV-IgG anti-VCA avidity aids the early and reliable diagnosis of primary EBV infection. $J$ Med Virol 2003;70:617-23.

11. Gärtner BC, Hess RD, Bandt D, Kruse A, Rethwilm A, Roemer K, Mueller-Lantzsch N. Evaluation of four commercially available Epstein-Barr virus enzyme immunoassays with an immunofluorescence assay as the reference method. Clin Diagn Lab Immunol 2003;10:78-82.

12. James JA, Harley JB, Scofield RH. Epstein-Barr virus and systemic lupus erythematosus. Curr Opin Rheumatol 2006;18:462-7.

13. Villegas E, Santiago O, Carrillo JA, Sorlózano A, Guerrero M, Fernández $\mathrm{O}$, Gutiérrez J. Low intrathecal immune response of anti-EBNA-1 antibodies and EBV DNA from multiple sclerosis patients. Diagn Microbiol Infect Dis 2011;70:85-90.

14. Castellazzi M, Tamborino C, Cani A, Negri E, Baldi E, Seraceni S, Tola MR, Granieri E, Contini C, Fainardi E. Epstein-Barr virus-specific antibody response in cerebrospinal fluid and serum of patients with multiple sclerosis. Mult Scler 2010;16:883-7.

15. Pohl D, Rostasy K, Jacobi C, Lange P, Nau R, Krone B, Hanefeld F. Intrathecal antibody production against Epstein-Barr and other neurotropic viruses in pediatric and adult onset multiple sclerosis. J Neurol 2010;257:212-6.

16. Sargsyan SA, Shearer AJ, Ritchie AM, Burgoon MP, Anderson S, Hemmer B, Stadelmann C, Gattenlöhner S, Owens GP, Gilden D, Bennett JL. Absence of Epstein-Barr virus in the brain and CSF of patients with multiple sclerosis. Neurology 2010;74:1127-35.

17. Jafari N, van Nierop GP, Verjans GM, Osterhaus AD, Middeldorp JM, Hintzen RQ. No evidence for intrathecal IgG synthesis to Epstein Barr virus nuclear antigen-1 in multiple sclerosis. J Clin Virol 2010;49:26-31.

18. Jaquiéry E, Jilek S, Schluep M, Meylan P, Lysandropoulos A, Pantaleo G, Du Pasquier RA. Intrathecal immune responses to EBV in early MS. Eur J Immunol 2010;40:878-87.

19. Cepok S, Zhou D, Srivastava R, Nessler S, Stei S, Büssow K, Sommer N, Hemmer B. Identification of Epstein-Barr virus proteins as putative targets of the immune response in multiple sclerosis. J Clin Invest 2005;115:1352-60.
20. Zivadinov R, Zorzon M, Weinstock-Guttman B, Serafin M, Bosco A, Bratina A, Maggiore C, Grop A, Tommasi MA, Srinivasaraghavan B, Ramanathan M. Epstein-Barr virus is associated with grey matter atrophy in multiple sclerosis. $J$ Neurol Neurosurg Psychiatry 2009;80:620-5

21. Brettschneider J, Tumani H, Kiechle U, Muche R, Richards G, Lehmensiek V, Ludolph AC, Otto M. IgG antibodies against measles, rubella, and varicella zoster virus predict conversion to multiple sclerosis in clinically isolated syndrome. PLoS One 2009;4:e7638.

22. Lindsey JW, Hatfield LM, Vu T. Epstein-Barr virus neutralizing and early antigen antibodies in multiple sclerosis. Eur $J$ Neurol 2010;17:1263-9.

23. Gray JJ. Avidity of EBV VCA-specific IgG antibodies: distinction between recent primary infection, past infection and reactivation. $J$ Virol Methods 1995;52:95-104.

24. Lünemann JD, Jelcic I, Roberts S, Lutterotti A, Tackenberg B, Martin R, Münz C. EBNA1-specific T cells from patients with multiple sclerosis cross react with myelin antigens and co-produce IFN-gamma and IL-2. J Exp Med 2008;205:1763-73.

25. Jilek S, Kuhle J, Meylan P, Reichhart MD, Pantaleo G, Du Pasquier RA. Severe post-EBV encephalopathy associated with myelin oligodendrocyte glycoprotein-specific immune response. J Neuroimmunol 2007;192:192-7.

26. Jilek S, Schluep M, Meylan P, Vingerhoets F, Guignard L, Monney A, Kleeberg J, Le Goff G, Pantaleo G, Du Pasquier RA. Strong EBV-specific $\mathrm{CD}^{+} \mathrm{T}$-cell response in patients with early multiple sclerosis. Brain 2008;131:1712-21.

27. Kiriyama T, Kataoka H, Kasai T, Nonomura A, Ueno S. Negative association of Epstein-Barr virus or herpes simplex virus-1 with tumefactive central nervous system inflammatory demyelinating disease. J Neurovirol 2010;16:466-71.

Cite this article as: Zhang SC, Liu L, Wang RJ, Tuo HZ, Guo YJ, Yi L, Wang DX, Wang JW. Detection of Epstein-Barr virus infection subtype in patients with multiple sclerosis by indirect immunofluorescence assay. Neuroimmunol Neuroinflammation 2014;1(1):24-8.

Source of Support: The work was supported by Beijing Natural Science Foundation (Nos. 7102040, 7132060), National Natural Science Foundation of China (Nos. 81041020, 81271311 and 81241039), Traditional Chinese Medicine, Beijing Technology Development Fund (No. SF-2007-III-22), Beijing Excellent Talent Foundation (No. 20071-D0300100062), the high-level technical training project funding of the Beijing health system (2011-3-004) and the preferential funding scheme for Beijing city staff to go abroad. Conflict of Interest: No.

Received: 04-05-2014; Accepted: 29-05-2014 